\title{
Information Evaluation: Teaching Students to Detect Bias, Fake, and Manipulation Ukrainian perspective
}

\author{
O. Vysotska ${ }^{1}$, S. Vysotska ${ }^{2}$ \\ Borys Grinchenko Kyiv University,Ukraine \\ Corresponding author. E-mail: cborysenko@gmail.com ${ }^{1}$, solomiiawysocka@gmail.com²
}

Paper received 16.08.20; Accepted for publication 08.09.20.

\begin{abstract}
https://doi.org/10.31174/SEND-PP2020-236VIII94-18
\end{abstract}
\begin{abstract}
In any part of today's digital world people easily get access to any information; they can disseminate it as well as create it by themselves. Modern people are overloaded with information; however, there is no guarantee that information they deal with is true. It may be biased, distorted or even untruthful, used for propaganda and manipulation. That makes the ability to critically evaluate information a survival skill, especially in Ukraine against which the war was waged, including the information one. Thus, there is urgent necessity to develop media literacy, to teach citizens, especially young people, to tell truth from fake and to detect bias and manipulation. In this respect it is required to include the course of media education as a compulsory one into school and university curricula, into programs of training and upgrading professionals, to offer online media education to those who wish to master it, etc. The analysis of relevant rich experience of western democracies in the area may be of great value for Ukraine in conditions of war and political instability. The present paper is aimed at presenting and analyzing available strategies and devices which may be used when teaching students and which make it possible to evaluate information, to identify its reliability, and to distinguish truth from propaganda, manipulation and falsehood.
\end{abstract}

Keywords: bias, evaluation, fake, information, manipulation, propaganda.

Feklusha, a pilgrim woman: No, my dear, owing to my weakness, I've never gone far away; but many a thing I've heard. They do say, my dear, there are countries where there are no Tsars of the true faith, but Sultans rule the lands. In one land there is the Sultan Mahnoot the Turk on the throne - and in another the Sultan Mahnoot the Persian. And they rule, my good girl, over all men, and whatever they decree it's always unrighteous. And they cannot, my dear, judge righteously in any one thing, such is the ban laid upon them. We have a just law, but they, my dear, an unjust law. Everything that is one way in our land is the very opposite in theirs. And all the judges with them, in their countries, are unjust too, so that, do you know, my girl, they even write in their petitions: "judge me, unjust judge!" And there is a country too where all the men have the heads of dogs.

Glasha: How do they come to have dogs' heads?

Feklusha: For their infidelity.

Glasha: Good-bye! (Exit Feklusha.) Only fancy that there are lands like that! There's no end to the marvels in the world. And here we sit at home and know nothing. A good thing it is to be sure, that there are pious folk; from time to time one hears what is being done in the light of day; if it weren't for them, we should live and die in our foolishness. (A. Ostrovskiy, the Storm, Act II, Scene I).

Introduction. Long-awaited reforms that are connected with the European choice of Ukraine are taking place in all spheres of the country's life, including education. One of the new things that are in the focus of the education system in the context of the European integration is media education - the development of media literacy and media culture.

Today people from all over the world, overloaded with information, have access to any information; more than that, they can even disseminate and create it by themselves. However, it may happen that the information they deal with is incorrect, biased, offensive, or infringes rights of others. The information they get may be untrue and fake. That makes the ability to critically evaluate the information a survival skill. So, it is quite evident that school students as well as university ones "need learn to evaluate information. In today's world of rapidly proliferating information in new electronic forms, individuals must be ready to make decisions about information reliability and credibility" [9:1]. Moreover, as Council of Europe media education experts claim, one of the main obstacles on the way of media literacy development is lack of information about it. There are lots of teachers who do not understand what media education is and why it is so important, for Ukraine, in particular. That puts forward an urgent demand in teachers who are able to properly navigate the vast information space: to sort out, evaluate, and analyze information in order "to help their students develop these skills" [8:8]. When there is no understanding, there is no motivation and no interest in it [28:9].

Thus, the importance of media education and its development, starting from primary school to the tertiary level and even the post-graduate one, is quite understandable and well-grounded in Ukraine. The present paper is aimed at presenting and analyzing available strategies and devices which make it possible to evaluate information, to identify its reliability, and to distinguish truth from propaganda, manipulation, and fake.

Materials and Methods. Media literacy, which media education results in, is generally defined in the documents of the European Union - one of the main supporters and propagandist of it - as "the ability to access the media, to understand and to critically evaluate different aspects of the media and media contents, and to create communications in a variety of contexts" [1:12]. In accordance with the definition, teachers, and their students, as well as public in general should:

- be able to use modern media and feel comfortable with them, from traditional newspapers to digital devices and applications, using them for work, life, and entertainment;

- adapt a critical approach to media, to their quality, form, and content;

- use media creatively as the development of IT makes it possible for mass users not only to perceive information as it was typical in the past, but also to create content and 
distribute it;

- be aware of copyright issues and netiquette in order to use modern media properly and in a civilized way [16:4].

In short, they should be able to access, analyze, evaluate and create messages in a variety of forms. These four components of media literacy - access, analysis, evaluation and content creation - constitute a skills-based approach to media education:

Each component supports the others as part of a nonlinear, dynamic learning process: learning to create content helps one to analyze that produced professionally by others; skills in analysis and evaluation open the doors to new uses of the internet, expanding access, and so forth [17:3].

Results and Discussions. As far as the situation in Ukraine is concerned, it should be noted that the country is not aside the process, and the National Concept of Education emphasizes that, first and foremost, media literacy is indispensable for making education correspond to changes in global and national economy, for perfecting the quality of education and for reorienting it at making national education system, its content and form, open to new knowledge brought by the rapidly changing modern world. So, moulding media awareness, i.e. media literacy is one of the key competences required for being successful in the new socio-economic reality [27:2]. Being media literate helps Ukrainians find, select, upgrade the required information and work with it without being "drowned" in the vast array of what is available. However, in the fast-changing information production and consuming context, teaching users to question the authority, objectivity or quality of mediated knowledge has become crucial.

The skill is very important in academic sphere for students who do a lot of online research, working on their essays, getting ready for seminars, or preparing various presentations. Coiro claims that you need to use high quality information as evidence to support your statements and arguments in order to produce high quality academic work. "You need to be certain that this information is relevant, accurate, up to date and objective. Having a systematic approach to evaluating information will help ensure this" [7:1].

In this regard, the first step the researchers are to make is to identify and understand their information needs in addition to what has been already obtained on the subject: what information sources (databases, library catalogs, encyclopedias, the Internet, etc.) are needed; how much information and what kind and type of it (experts' opinion, examples, statistical data, etc.) is required; what the intended audience is; when and where the information was published.

Researchers are responsible for the information included or referred to in their assignment. It should be credible, and every piece of information used, every source of information mentioned, and every author cited are to be verified. There are online tools as well as recommendations and tips on how to evaluate the credibility of the sources of information, of web pages, the quality of web content, etc. Various checklists and guidelines may be applied, for example, the CRAAP (Currency, Relevance, Authority, Accuracy, Purpose of the information) - a checklist offered by Meriam Library, California State University [12], or the CARS (Credibility, Accuracy, Reasonableness, Support) checklist offered by experts from the University of
Wolverhampton, UK. Their adapted variants are presented below:

Credibility implies checking information about the author's education, training and experience in the field as well as his/her standpoint among peers, title, and career history. When checking accuracy and currency, users pay attention to the date of the information, whether it is current or outdated, whether it is detailed, exact and comprehensive, and the extent to which factual information and details can be verified by consulting alternative and/or primary sources. Reasonableness means whether the article presents an argument that is balanced, reasonable, objective, and consistent. It is also recommended to analyze the support: where the information comes from, whether the sources for the information are listed, whether a bibliography is available, what support the author gives to the information provided, and whether contact information for the author is included.

Those who work with information taken from the Internet should remember that, though the Internet is an invaluable source of any kind of information for research, there is no, so to speak, "gate keeper:" it is not a problem to open a web page, and anyone can place information on it. Then it is quite logical that there should be strict "quality control" and fact-checking on the part of those who use this information for research [7:1].

"The quality of our thinking is given in the quality of our questions," as experts from the Foundation of Critical Thinking remark. They propose a set of questions that may be applied by teachers and their students at a Media Literacy class when evaluating the content of the information found. It summarizes the recommendations presented above:

How could we check on that? How could we find out if it is true? How could we verify or test that? Where could we get more details? What factors make this a difficult problem? Do we need to look at it from another perspective? Do we need to consider another point of view? Does the idea make sense? Does what is presented follow from the evidence? Is this the most important problem to consider? Which of these facts are the most important? (Adapted from: [22]).

Coiro offers another set of strategies - a kind of "thinking prompts" to consider in class. They are focused on the reliability of sources of information and may help those who would like to think critically:

Is this site relevant to my needs and purpose? What is the purpose of this site? Who created the information at this site, and what is this person's level of expertise? When was the information at this site updated? Where can I go to check the accuracy of this information? Why did this person or group put this information on the Internet? Does the website present only one side of the issue, or are multiple perspectives provided? How are information and/or images on this site shaped by the author's stance? Is there anyone who might be offended or hurt by the information on this site? How can I connect these ideas to my own questions and interpretations? [7:3].

Unfortunately, it often happens that students pay most attention to the publication content relevance, leaving its quality and credibility aside, leaving out its authors and their reputation, venue, evidence, and reasoning support. Thus, at practical classes students should be taught to be 
"healthy skeptical" while searching for and analyzing the material and be able to verify the information obtained from multiple and sometimes controversial sources before making the decision whether to accept it or refute.

It is advisable to compare information across sources and to verify such aspects as who created the Website or posted a comment; what information is available about them (names, positions, affiliation, areas of interest, achievements in the field); whether contact information provided (email, telephone number, address); whether names, places, dates are presented and presented in an accurate way; whether the information is publish on an appropriate site. For instance, serious research article will not appear on an entertainment site. The domain name corresponds to the nature of the site and the information published on it. Such names as *.com, *.org, *.net may belong to any organization or even to private persons, so governmental organizations do not use them to publish official information. Thus, it may be assumed that what is published on them is unlikely to be official and sometimes is not credible [2:30]. It is also possible to check the owners of the domain, when and where it was registered, bought, by who, etc. Some Internet sites may help with such verification (See Appendix 1).

There are organizations that may assist in the process of verification. They monitor media publications and compile ratings of mass media, indicating those which are trustworthy and which are not, as it may happen that they, especially online publications and Internet sites, are not what they pretend or seem to be. They "flood their users with all sorts of information, much may be contradictory, abundant with interpretations of past or current events, which may also aim for manipulation of people's perception" [8:5]. Michael Lynch, a journalist and a philosopher who studies technological change, noted that the Internet is "both the world's best fact-checker and the world's best bias confirmer - often at the same time" [20:4]. The New York Times correspondent continues:

Never we had so much information at our fingertips. Whether this bounty will make us smarter and better informed or more ignorant and narrow-minded will depend on our awareness of this problem and our educational response (emphasis mine) to it. At present, we worry that democracy is threatened by the ease at which disinformation about civic issues is allowed to spread and flourish [Ib.].

Therefore, information consumers, and younger generation, in particular, should be taught and learn to differentiate between high-quality, reliable information and substandard one, lies, bias and fakes. The development of the skill is urgent for Ukraine hence it turns media literacy and therefore media education into a tool for counteracting propaganda and information aggression as a component of the hybrid war unleashed against the country [28:1]. What is more, election campaigns, presidential, parliamentary, and local ones have already become an attribute of Ukrainian political life, with candidates trying to win by fair means or foul, even resorting to bias and fake, skillfully manipulating voters. Regretfully, critical thinking development and counteraction to enemies' hostile propaganda have not been paid enough attention to. Consequently, the mentality of some part of the citizens of Ukraine is still Soviet; the influence of Russian propaganda is very strong and its seeds fall on fertile soil. Then the question arises how to detect information which is biased, i.e. not objective, distorted or twisted, propaganda, and manipulation.

According to dictionary definitions "biased information" means one-sided, partisan, prejudiced, prejudicial, prepossessed, tendentious (Dictionary of Synonyms). Bias is showing an opinion about something that is not based on all of the facts. Different points of view, the way a person sees the world which is based on that person's beliefs and life experiences, may be biased. There are several types of bias: bias by omission, bias by placement, bias by spin, and bias by confirmation.

If some information is not covered by a publication, and accordingly may not be perceived as important, bias by omission is presented. The placement or location of the story on the front page sends the message that the story is very important. If it is not on the main page, it may not be noticed and may be omitted as something not significant. This is bias by placement. The third type of bias is bias by spin. Spin means presenting exclusively positive or negative opinions or points of view about a subject, a person, some events, etc. in order to change the opinion of the audience (English for Media Online Course, 2018). There is also bias by confirmation. It is connected with a limited information space - the so-called "filter bubble": people are attracted to information which is connected, reflects, and confirms their own point of view or opinion. It may happen that people get into a filter bubble which is a result of their personalized search on the Internet: the site algorithm analyzes what sites a particular user visits, what information he/she is interested in, and offers information corresponding to this interest, separating the information the user disagrees with.

Bias affects the process of decision making, when defining and assessing alternatives or selecting a course of actions. To make thoughtful and objective decisions, informed consumers, in particular, students, ask themselves what points of view are omitted from the publication. If bias by placement is detected, one may ask how important the information is for his/her personal life, for the region, for the country, for society in general to make the right decision. If there is bias by spin, it may be recommended to search for other publications on the problem [Ib.]. To avoid bias by omission or getting into a filter bubble, triangulation may be recommended, that is searching for information from different sources.

As a rule, journalists emphasize that their responsibility is to present comprehensive information and different points of view, that their duty is to cover facts, being as objective as possible. It is difficult not to agree with that and, moreover, that is what is required by journalism standards, BBC standards for journalism, in particular. When presenting information, journalists are to be independent, impartial, and honest:

Impartiality lies at the core of the BBC's commitment to its audiences. We [journalists] will apply due impartiality to our subject matter and will reflect a breadth and diversity of opinion across our output as a whole, over an appropriate period, so that no significant strand of thought is knowingly unreflected or under-represented. We will be fair and open-minded when examining evidence and weighing material facts [3].

On the other hand, writing about media representatives' duties and accountability, S. Kaufman, a journalist himself, 
notes, citing K.Z. Smith, American journalism veteran, that when voters are heading to the polls, the job of journalists is "educating the citizenry [...] with information so they can make appropriate decisions." With the pressures reporters face from censorship, bribes and threats against their lives, that job is not always easy. K. Z. Smith voiced alarm at the fact that media may be controlled by government, corporate or private interest groups that paid reporters. Nevertheless, in a democratic state, the press should "serve as a watchdog on the government and inform the citizens so they can make the appropriate decisions about their government and their way of life," he added. Addressing journalists, he said:

If you chase any other interest, if that is not your motive, and your motive is to see that certain people get elected and to report in a way that is not going to be accurate, and is not going to be fair, then you're not serving your function as a journalist. [...] If there is a time in which the press needs to step up and be accountable and do the right thing by being accurate and being fair, it's absolutely, positively during an election process. Otherwise, you're cheating the citizens of information. You're cheating them out of opportunities to make decisions that affect them (cited in: [15]).

Recommendations. However, it happens that some Ukrainian journalists, trying to be impartial, completely forget about the fact that the country, Ukraine, has been war-ridden for more than five years. It was attacked and occupied; thousands of Ukrainians have been killed and wounded; thousands of houses, businesses and enterprises have been ruined and robbed. A controversial question may be asked whether it is possible to preserve impartiality and to give the floor and media space to the enemy, to those who support the enemy, or those who do not care. It seems that everything covered and presented in Ukrainian media today should be presented from the Ukrainian-centered position in order to do the utmost possible to make people understand the situation, be aware of propaganda, to strengthen and develop civic consciousness and patriotism, especially at the time when biased information and various fakes have become widely used for manipulation.

Fake stuff has entered people's life, starting with replicas of brand clothes and accessories and finishing with misleading falsified facts and twisted opinions and ideas. The phenomenon has become so wide-spread that "posttruth" and "fake news" were named phrases of the year by Oxford and Collins Dictionaries in 2016-2017 [25; 14].

Fakes may be quite innocent, just to attract attention or to make publications, particular people, events, etc. popular. However, when it is made for propaganda, manipulation and disinformation, it is more serious. The dramatic example is fakes that accompany the aggression and the hybrid war waged against Ukraine in 214 when the enemy resorts to presenting knowingly false information for manipulating people, the information that arises hatred and violence. They present news concerning Ukraine contrary to what is taking place in reality. They try to camouflage the aggression and the occupation of the territory of the neighbouring country and present it as a civil war that is taking place inside Ukraine. That misleads people. Those who have been taught to think critically, understand that when designed to deceive users for political purposes, digital gossip falls under 'disinformation' - the dissemination of deliberately false information which non-state and state actors can use to undermine adversaries. The Kremlin continues its disinformation campaigns in its ongoing hybrid war against Ukraine, and is applying them in its 'holistic' information warfare against the West [4:2].

It may be surprising, but false news spreads faster, farther and deeper than true news, especially when it deals with the information disseminated online. The researchers from the Massachusetts Institute of Technology found out that this statement is applied to any subject they studied: to politics, business, science, technology, etc. They analyzed the fact and proved that "false claims were 70 percent more likely than the truth to be shared on Twitter. True stories were rarely retweeted by more than 1,000 people, but the top one percent of false stories were routinely shared by 1,000 to 100,000 people. And it took true stories about six times as long as false ones to reach 1,500 people" [19]. Psychologists investigate the phenomenon trying to explain it. However, the message for general public is as follows: check information before relying on it, working with it or disseminating it.

Information may be classified as true or false, with the help of special fact-checking sites and organizations. There are also special Internet sites to check photographs. Every day there appear specific tools to detect fakes, and every day there appear new tools to create fakes for disinformation which makes it possible to create fake videos that, for example, can represent practically any person behaving and saying what is required for disinformation.

If some information is important, but doubtful, or suspicion arises, it may be recommended to apply the ESCAPE test to check and evaluate it (Evaluation, Source, Context, Audience, Purpose, Execution).

The procedure starts with the evaluation of places, names, documents, statistics mentioned in the publication. The source of information is analyzed too - who made the piece of information, what the initial source of it was. Huge information agencies and their online publications refer to those that may be trusted. The author's credentials and what information is presented about him/her should be also checked as well as the site or the source of information if they are available; quotations require scrupulous checking before making references to them or disseminating them. The date of publication is important too: what context the publication was made in; what the big picture is; whether there are other publications on the same event or problem. On the other hand, the more fuss is about something, the stronger probability is that people will believe it. What audience, what group of people the information is intended for and appeals to and the purpose - why it was published - are to be taken into consideration. The execution of the publication deserves attention: how the information is presented, i.e. its style, grammar, layout, tone, image choices, etc. Emotionally coloured vocabulary which causes strong feelings and emotions signals that the information may be fake. The same refers to mistakes or inaccurate layout. It is also recommended to look through commentaries of the publication. It may happen that the information has already been verified and refuted. Other signals of fakes are exaggerations, a lot of figures, sophisticated terms, blaming opponents, and generalizations.

The question arises why people become victims of fake information and manipulation by media. Critic and linguist 
Noam Chomsky noted that media has created or destroyed social movements, justified wars, and caused financial crises [6]. He compiled the list of strategies which are usually resorted to by those who aim at manipulating people: distract, create problems and then solve them, apply the gradual strategy and the strategy of deferring, go to the public as a little child, use the emotional side more than the reflection, keep public in ignorance and mediocrity, encourage the public to be complacent with mediocrity, strengthen self-blame [ibid].

Practically all of them have been employed in the USSR and its followers that have monopolized the supply of information in their countries, and are actively resorted to by candidates during election campaigns in Ukraine today. The examples of the application of the strategies are numerous.

Media literacy is a powerful tool for developing awareness, for molding Ukrainian identity, patriotism, internationalism and intercultural competence. It helps overcome bias and fake and develops understanding that all people have the right to respect of their human dignity, to communication and cooperation with other people, respecting and valuing the diversity of their cultural background [8:6].

It should be noted that media literacy issues have attracted attention in present-day Ukraine, and positive tendencies may be observed. More and more lawyers, journalists, politicians touch upon and discuss media education issues. There have appeared online courses for those who want to develop media literacy skills, do not want to be deceived and try to learn how to tell lies from the truth (see Appendix, 2). Media Education course is taught at some schools and universities as a selective course or its elements are incorporated into some other subjects [18].

At the same time, the war in the East of the country, and lack of resources and experience impose particular constraints on the process. At present, media education is not taught as a compulsory separate subject. However, it is possible, at least, to include it as a must into such courses as Information Science, Ukrainian, Foreign Languages, Social Studies, with its main task being teaching students to analyze media, employing different criteria, and to differentiate between quality and falsified information. The situation in the country could have been completely different if Ukrainians had been more aware of propaganda and manipulation techniques. Then they could understand what is true and what is simulacrius. They would understand essentials of western democracies, would be able to reflect on and evaluate the Soviet past and what "Russian spring" and "Russian world" bring to people. They would not have turned into the fifth column inside the country. They would not blame Ukraine for "waging the war" and would not call for compromise with the enemy at any rate.

Thus, it is evident that media literacy has become vital for Ukraine's survival as a sovereign independent state. Successful experience of western countries in the area may be of great value. It should be analyzed and employed as well as strategies and tactics for developing patriotism in a multinational country. European and American curricula, syllabuses, forms and methods of teaching and learning should be thoroughly studied and compared with what has been done in this area in Ukraine. The further research will be focused on that and hopefully result in working out recommendation for Ukrainian media educators.

Conclusion. The advent of digital technology has brought not only opportunities, but challenges and problems too, with "the Internet being turned into the field of political and ideological battles" [8:5]. In this regard it is impossible not to agree with Hartly, expert in media literacy, on the point that "literacy is ideologically and politically charged - it can be used as a means of social control or regulation, but also as a progressive weapon in the struggle for emancipation" $[1: 136]$. As far as teaching and learning are concerned, the following should be kept in mind:

A teacher must be well prepared to equip students with skills to search and compare information on different perspectives, analyze one-sided representations and identify cases of the manipulative use of social media. The teacher must possess intercultural competence and know how to support the development of such competence among the students [8:5].

Due to that, media education is referred to as one of the basic skills of the 21 st century [op. cit., p. 7] since it helps formulate opinions and understand points of view.

On the other hand, media literate people are aware of their responsibility for the information they create and disseminate. They are able to identify the role of media in culture and the fact that it may shape their understanding of the world and compel to act or think in certain ways. Media literacy helps people become smart consumers of information and learn to think critically about it, being able to identify bias and manipulation [26].

Media education lays the foundation of information consumption and should permeate all stages of education, curricula, development of teaching materials, starting with primary education to the tertiary level one as well as teacher training, informal education, and life-long learning since it guarantees indispensable rights of modern citizens - the right to get information and the right to express oneself, those instruments of democracy implementation [11:7].

It happens that media illiterate people are like pilgrim woman Feklusha and her interlocutor Glasha from The Storm by A. Ostrovskiy (the Epigraph). They are not able to perceive information properly; they are not able to understand it. What is more, they spread fakes. As result, under the influence of powerful enemy's propaganda and disinformation, the country may turn into a boat, with a buccaneer's axe placed under the compass, without any ability to identify the course and confront to the enemy (L. Kostenko's metaphor). Thus, there is vital necessity to teach citizens of the country, and not only school or university students, to analyze MM information, to filter and assess it. That is why it is expedient for a serious state media education campaign to be launched in Ukraine as a component of state strategy in the realm of information policy.

\section{REFERENCES}

1. Aufderheide, P. (1993). Media Literacy: A report of the national leadership conference on media literacy. Washington, D.C.: The Aspen Institute.

2. Bartlett, J. \& C. Miller. (2011). Truth, Lies and the Internet. A
report into young people's digital fluency. London: Demos,
September.
Retrieved 
http://www.demos.co.uk/files/Truth_-_web.pdf

3. BBC Editorial Guidelines. (2019). Retrieved from https://www.bbc.co.uk/editorialguidelines/guidelines/bbc-editorial-values/editorial-values

4. Bentzen, N. (November, 2017). At a glance. Disinformation, 'fake news' and the EU's response. / European Parliamentary Research Service. Retrieved from http://www.europarl.europa.eu/Reg-

Data/etudes/ATAG/2017/608805/EPRS_ATA(2017)608805_ EN.pdf

5. Buckingham, D. (1998). Media education in the UK: Moving beyond protectionism. Journal of Communication, 48 (1), 3342.

6. Chomsky, N. (2019, January 10). 10 strategies of manipulation by the media. Retrieved from https://parisis.files.wordpress.com/2011/01/noam-chomsky

7. Coiro, J. (2014, April 7, updated 2017, August 29). Teaching Adolescents How to Evaluate the Quality of Online Information. Edutopia. Retrieved from https://www.edutopia.org/blog/evaluating-quality-of-online-info-julie-coiro

8. Council of Europe. (2018, September 20). How to Develop the Ability of Students to Assess Information from Media and Social Networks? A tool for teachers developed with the participation of Belarus, Georgia, Lithuania and the Russian Federation. Retrieved from https://pjp-eu.coe.int/documents/1417855/8919103/How+to+develop+the+ability+of+students+to+assess+information+from+media+and+social+networks+-a+methodological+tool.pdf/353e08f2-6722-4bb0-b905-4ce567b6596d pdf

9. Fitzgerald, M. A. (1999). Evaluating Information: An Information Literacy Challenge. School Library Media Research, 1999, vol. 2, 1-35

10. European Commission. (2007). A European Approach to Media Literacy in the Digital Environment. URL (consulted July, 2009). Retrieved from http://ec.europa.eu/avpolicy/media_literacy/docs/com/en.pdf

11. European Commission. (2012). Freedom of Expression, Media and Digital Communications. A practical guide. Retrieved from https://ec.europa.eu/europeaid/sites/devco/files/studyfreedom-expression-communication-guide-201212_en_1.pdf

12. Evaluating Literacy. (2019). Retrieved from https://www.csuchico.edu/lins/handouts/eval_websites.pdf

13. Hartley, J. (2002). Communication, Cultural and Media Studies. The Key Concepts. London and New York: Routledge. Retrieved from http://library.uniteddiversity.coop/Media_and_Free_Culture/Communication_Culture_and_Media_Studies-John_Hartley.pdf

14. Hunt, J. (November 2, 2017). 'Fake news' named Collins Dictionary's official Word of the Year for 2017. The Independent. Retrieved https://www.independent.co.uk/news/uk/home-news/fakenews-word-of-the-year-2017-collins-dictionary-donaldtrump-kellyanne-conway-antifa-corbynmania-a8032751.html

15. Kaufman, S. (2016, April 29). For the press, elections are a test of accountability / Share America. Retrieved from https://share.america.gov/elections-are-test-of-press-accountability/

16. Koltay, T. (2011, March). The Media and the Literacies: Media Literacy, Information Literacy, Digital Literacy. Media culture and society. Retrieved from https://www.researchgate.net/publication/263652378_The_Media_and_the_Literacies_Media_Literacy_Information_Literacy_Digital_Literacy

17. Levingstone, S. (2004). LSE Research Online. Media literacy and the challenge of new information and communication technologies. Communication review, 1 (7), 3-14. Retrieved from http://eprints.lse.ac.uk/1017

18. Ligostova, O. (May 2, 2019). More than half a thousand schools in Ukraine will be taught to recognize fakes and misinformation. Retrieved from Retrieved from https://ukrainian.voanews.com/a/learn-and-discern/4900832.html

19. Lohr, S. (2018, March 8). It's True: False News Spreads Faster and Wider. And Humans Are to Blame. The New York Times. Retrieved from https://www.nytimes.com/2018/03/08/technology/twitter-fake-news-research.html

20. Lynch, M. (2016, March 9). Googling is Believing: Trumping the Informed Citizen. New York Times. Retrieved from https://opinionator.blogs.nytimes.com/2016/03/09/googlingis-believing-trumping-the-informed-citizen/).

21. Media Literacy. (2018, May 23.) Retrieved from https://www.edutopia.org/blog/evaluating-quality-of-onlineinfo-julie-coiro

22. Paul, R.V., \& Elder, L. (2004). The Thinker's Guide to the Nature and Functions of Critical and Creative thinking. Santa Rosa, CA: Foundation for Critical Thinking. Retrieved from www.criticalthinking.org

23. Schulten, K. \& Chisty Brown, A. (2017, January 19). Evaluating Sources in a 'Post-Truth' World: Ideas for Teaching and Learning About Fake News. The New York Times. Retrieved from https://www.nytimes.com/2017/01/19/learning/lessonplans/evaluating-sources-in-a-post-truth-world-ideas-forteaching-and-learning-about-fake-news.html

24. Skills for Learning. Guide to evaluating information. (2018, March). Wolverhampton: University of Wolverhampton. Retrieved from https://www.wlv.ac.uk/lib/media/departments/lis/skills/study-guides/LS014-Guide-to-Evaluating-Inform

25. Wang, A.B. (November 16, 2016) Post-truth named word of 2016 year by Oxford Dictionaries. The Washington Post. Retrieved from https://www.washingtonpost.com/news/thefix/wp/2016/11/16/post-truth-named-2016-word-of-the-yearby-oxford-dictionaries/?utm_term $=.9 \mathrm{fc} 2 \mathrm{f} 3 \mathrm{e} 592 \mathrm{c} 5$

26. What is media literacy, and why is it important? (2019, January 11). Retrieved from https://www.commonsensemedia.org/news-and-media-literacy/what-is-media-literacy-andwhy-is-it-important

27. The Concept of Media Literacy Introduction in Ukraine (new edition). (2016, April 24). Retrieved from http://osvita.mediasapiens.ua/mediaprosvita/mediaosvita/kont septsiya_vprovadzhennya_mediaosviti_v_ukraini_nova_reda ktsiya/. Published in Ukrainian.

28. National Institute for Strategic research. (2018). Media Education as a Factor of Improving the Quality of Education and a Means for Resisting Humanitarian Aggression. Analytical Memorandum. Retrieved from http://www.niss.gov.ua/articles/1795 . Published in Ukrainian.

\section{Appendix}

1. Examples of sites for information verification: http://who.is; http://whois.domaintools.com; https://whois.net (FactCheck course); Nopes; PolitiFact; FactCheck.org.; Youtube DataViewer; youtube.github.io/geo-search-tool/search.html. InVid helps to check photgraphs. Deepfakes, on the contrary, helps to produce fake videos which can represent practically any person behaving and saying what is required for disinformation.

2. Examples of online courses on Media Education: FactCheck, 2018, developed by VoxUkraine supported by Swedish Embassy (https://courses.ed-era.com/activate/1fa0eafd83054fc588d020c1000366fel); English for Media, 2018, University of Pennsylvania (https://www.coursera.org/learn/media); Real Media Literacy for a Fake News World Program, 2019, U.S. Embassy in Ukraine in collaboration with Newseum (https://www.prostir.ua/?grants=oholoshujemo-nabir-uchasnykiv-treninhiv-v-ramkah-prohramy-realmedia-literacy-for-a-fake-news-world). 